\title{
Analysis and Discussion of Trace Elements in Teeth of Different Animal Species
}

\author{
F. O. Falla-Sotelo, M. A. Rizzutto, M. H. Tabacniks, N. Added, M. D. L. Barbosa, \\ Instituto de Física, Universidade de São Paulo, São Paulo, SP, Brazil \\ R. A. Markarian, A. Quinelato, M. Mori, and M. Youssef \\ Faculdade de Odontologia, Universidade de São Paulo, São Paulo, SP, Brazil
}

Received on 15 June, 2005

\begin{abstract}
Human, bovine and swine teeth were analyzed by Proton Induced X-ray Emission (PIXE). The aim of this work was to determine the concentration of trace elements in enamel and dentine of different animal species. PIXE analysis was carried out at the Laboratrio de Anlise de Materiais por Feixes Inicos da USP (LAMFI) using a $2.4 \mathrm{MeV}$ proton beam to probe the samples. Healthy teeth from So Paulo region were analyzed. Thirteen elements were measured and quantified in the samples: $\mathrm{P}, \mathrm{S}, \mathrm{Cl}, \mathrm{K}, \mathrm{Ca}, \mathrm{Cr}, \mathrm{Mn}, \mathrm{Fe}, \mathrm{Ni}, \mathrm{Cu}, \mathrm{Zn}, \mathrm{Sr}$ and $\mathrm{Ba}$. The measured ratio of $\mathrm{Ca}: \mathrm{P}$ in dentine and enamel teeth is the same expected for hydroxyapatite: 2.13 , for all three types. Trace element concentrations were found to be very similar between the three species, except for S, Cl, $\mathrm{Fe}, \mathrm{Cu}$ and $\mathrm{Sr}$. $\mathrm{Ni}$ and $\mathrm{Cu}$ concentrations were found to be close to $1 \mathrm{ppm}$, which is also close to the detection limits of the SP-PIXE system.
\end{abstract}

\section{INTRODUCTION}

Trace elements play an important and complex role in the human and animal metabolism. The trace elements in teeth have been examined for a number of reasons, for example there are some studies of dental health where trace element concentrations have been correlated with the presence of dental caries [1-3]. Some elements such as $\mathrm{Al}, \mathrm{Fe}$ and $\mathrm{Sr}$ are caries inhibitory and $\mathrm{Cu}, \mathrm{Mn}$ and $\mathrm{Cd}$ are caries promoting [2], however the combinations of $\mathrm{Mn}$ and $\mathrm{Cd}$ may have inhibitory role, while $\mathrm{Al}$ and $\mathrm{Sr}$ can promote caries. The mineral tissue of the tooth consists of hydroxyapatite crystals $\mathrm{Ca}_{10}\left(\mathrm{PO}_{4}\right)_{6}(\mathrm{OH})_{2}$ with incorporated trace elements, which can provide information of the habitat environment or dietary habits. The tooth is a bio-indicator of great interest because it contains information on deposited elements in the tooth material. Mammalian teeth contain three tissues such as enamel, dentine and cementum. In order to find compatible human teeth for substitution in the dentistry laboratory practice and chemical tests, a comparison of the trace elements in the enamel and dentine teeth was made, between the human and animal teeth (swine and bovine). This work was performed with Particle Induced X-ray Emission (PIXE) spectroscopic technique [4]. The trace elements concentrations in enamel and dentine of human, swine and bovine teeth were obtained with the thick target PIXE (ttPIXE) analysis calculated for a given matrix as hydroxyapatite throught the CLARA program [5].

\section{EXPERIMENTAL PROCEDURE}

Healthy teeth were collected from So Paulo region. Bovine incisive, swine molars and human molars (control group), were divided in three groups of ten teeth. All teeth were weighed and sterilized using one autoclave cycle and finally stored in dry air at $4^{\circ} \mathrm{C}$ in individual containers until analysis. To obtain a flat surface with the exposed dentine, the molar's crown was sliced and the bovine incisive had their buccal fa- ces cut with a diamond disk, to avoid metal contamination of the cut surface. The PIXE measurement of the samples was performed at the LAMFI Laboratory. Samples were irradiated in vacuum with a $2.4 \mathrm{MeV}$ proton beam with $4 \mathrm{~mm}$ diameter. The sliced teeth were mounted on a multiposition target tower at the center of the PIXE chamber [6]. In the reaction chamber the target was positioned at $135^{\circ}$ with respect to the proton beam, the target tower allows vertical translation. Typical beam currents used were about a few nA to reduce dead time and pile-up. The acquisition time was 1200 seconds for each sample. The X-rays were observed with a $\mathrm{Si}(\mathrm{Li})$ detector with a resolution of about $145 \mathrm{eV}$ at $\mathrm{MnK}_{\alpha}$. The X-ray spectra were optimized for detection of elements above $\mathrm{P}$, and a "funny filter" made of Mylar (300 $\mu m$ thick with a $10 \%$ hole and a plain Mylar 50 $\mu \mathrm{m}$ thick) was placed between the target and detector to reduce the count-rate of $\mathrm{Ca}-\mathrm{K}_{\alpha}$ peak. The PIXE spectra were analyzed by AXIL-X-Ray analysis software [7]. The program evaluates the integral of thick target correction factor, using Newton-Cotes algorithm [8]. Total Xray ionization cross sections are calculated using Johansson and Johansson [9] polynomial fit. X-ray intensity ratios were taken from Scofield [10] and Perujo [11] while the fluorescence yields are from Bambyneck [12]. Stopping powers for protons up to $10 \mathrm{MeV}$, are calculated using the fitted curve given by Ziegler et al. [13]. Mass absorption coefficients are calculated using the XCOM software developed by Berger and Hubbell [14].

\section{RESULTS AND DISCUSSION}

The enamel and dentine mean trace element concentration of the three teeth species are summarized in figure 1 and 2 . The dentine and enamel comparison between the three species shows no statistical differences among the major concentration elements $(\mathrm{Ca}$ and $\mathrm{P})$.

Trace element concentrations were found to be very similar between the three species, except for $\mathrm{Mn}, \mathrm{Cu}$ and $\mathrm{Ni}$ for enamel and $\mathrm{Cu}$ for dentine. Concentrations of $\mathrm{Cr}, \mathrm{Ni}$ and $\mathrm{Cu}$ were 


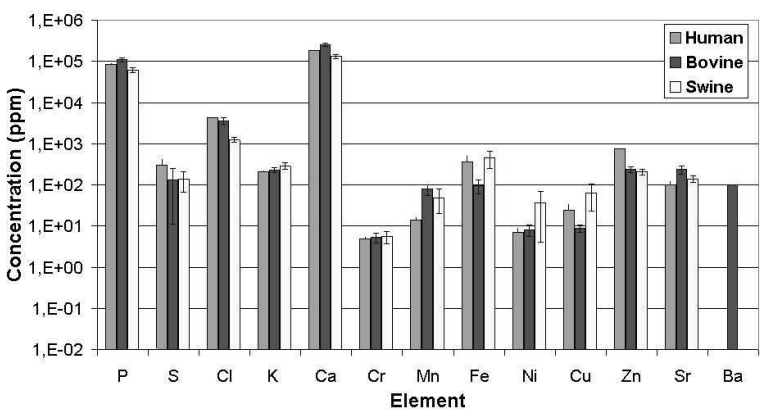

FIG. 1: Mean trace element concentration (in ppm) in enamel of human, swine and bovine teeth. Lines on top of each bar indicate sample mean standard deviation.

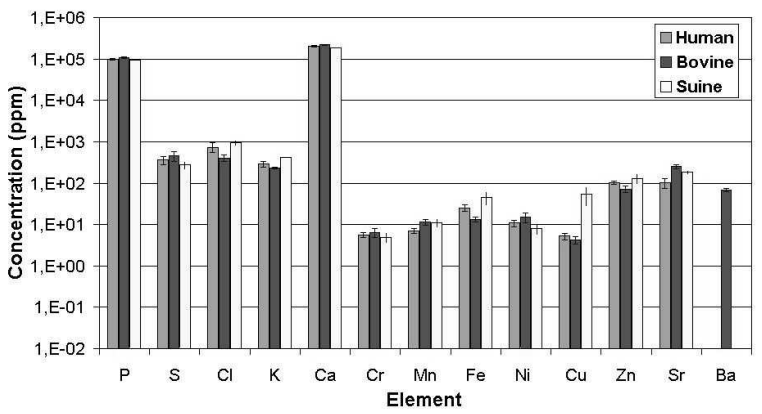

FIG. 2: Mean trace element concentration (in ppm) in dentine of human, swine and bovine teeth. Lines on top of each bar indicate sample mean standard deviation. found to be close to $1 \mathrm{ppm}$, which is also close to the detection limits of the SP-PIXE system. The bovine dentine and enamel shows clear evidence of Ba concentration. Concentrations of $\mathrm{Cl}, \mathrm{Mn}, \mathrm{Fe}, \mathrm{Cu}$ and $\mathrm{Zn}$ are higher in enamel compared with dentine. The measured ratio of $\mathrm{Ca}: \mathrm{P}=2.17$ (22) and 2.13(38) in human, 2.32(19) and 2.08(18) in bovine and 2.21(19) and 1.92(8) in swine in enamel and dentine respectively, is similar to the expected data for hydroxyapatite: 2.13 .

\section{CONCLUSION}

Trace elements in dentine and enamel for human, bovine and swine teeth were compared for the first time. Results from this study shows no statistical differences among the major concentration elements ( $\mathrm{Ca}$ and $\mathrm{P})$. Thirteen elements were measured and quantified in the samples: $\mathrm{P}, \mathrm{S}, \mathrm{Cl}, \mathrm{K}, \mathrm{Ca}, \mathrm{Cr}$, $\mathrm{Mn}, \mathrm{Fe}, \mathrm{Ni}, \mathrm{Cu}, \mathrm{Zn}, \mathrm{Sr}$ and $\mathrm{Ba}$. This study demonstrates that $\mathrm{Ba}$ exist only in bovine teeth. The measured ratio $\mathrm{Ca}: \mathrm{P}$ in enamel and dentine respectively, is similar to the expected data for hydroxyapatite.

\section{Acknowledgments}

M.A.R and M.H.T. authors wish to grateful to FAPESP for financial support. F.O.F.S, M.H.T. and N.A. acknowledge $\mathrm{CNPq}$ for financial support.
[1] M. A. Chaudhri, and T. Ainsworth, Nucl Instr. Meth. 181, 333 (1981).

[2] H. J. Annegarn, A. Jodaikin, P. E. Cleaton-Jones, J. P. F. Sellschop, and C. C. P. Madiba, Nucl Instr. Meth. 181, 323 (1981).

[3] M. E. Curzon, and D. C. Crocker, Arch. Oral Biol. 23, 647 (1978).

[4] S. A. E. Johansson and J. L. Campbell, PIXE: A novel technique for elemental analysis (John Wiley\&Sons, Inc., 1988).

[5] J. Aburaya, M. H. Tabacniks, M. D. L. Barbosa, N. Added, M. A. Rizzutto, and M. D. L. Barbosa, Submitted to Nucl. Instr. and Meth. (2005).

[6] M. H. Tabacniks, Physics Institute Report - IF/USP 1469, 50 (2000).

[7] P. Van Espen, H. Nullens, and F. Adams, Nucl. Instr. and Meth. 145, 579 (1977).

[8] A. Hadding, Anorg. Allgerm. Chem 122, 195 (1922).
[9] S. A. E. Johansson and T. B. Johansson, Nucl. Instr. and Meth. 137, 476 (1976).

[10] J. H. Scofield, Phys. Ver. A9, 1041 (1974).

[11] A. Perujo, J. A. Maxwell, W. J. Teesdale, and J. L Campbell, J.Phys. B20, 4973 (1987).

[12] W. Bambyneck, private comunication of material presented verbally at the International Conference on $X$-ray and Inner Shell Process in Atoms, Molecules and Solids, University of Leipzig, (1984).

[13] J. F. Ziegler, J. P. Biersack, and U. Littmark, The Stopping and Range of Ions in Solids Nucl. Instr. Meth. 1, (Pergamon Press, (1985).

[14] M. J. Berger and J. H. Hubbell, XCom Photon Cross Sections on a Personal Computer, Center for Radiation Research NBS (National Bureau of Standards), (1988). 